\title{
Based on the Finite Element Limit Equilibrium Method Analyze Earth-Rock Dam Slope Stability Zan $\mathrm{LI}^{1, \mathrm{a},{ }^{\star}, \mathrm{Li}-\text { Xiang ZHANG }}{ }^{2, \mathrm{~b}}$, Meng-Ying $\mathrm{BIAN}^{3}$ \\ ${ }^{1,2,3}$ Faculty of Civil Engineering, Kunming University of Science and Technology, Kunming, 650500 , China \\ alizandream@126.com, ${ }^{\mathrm{b}} \mathrm{z} \mid \mathrm{xzcc} @ 126 . c o m$ \\ ${ }^{*}$ Corresponding author
}

Keywords: Finite Element Limit Equilibrium Method, Limit Equilibrium Method, Slope Stability, Safety Factor.

\begin{abstract}
Based on finite element limit equilibrium method, taking a core embankment dam construction period as the research object and studying on the dam slope stability. Combined with SIGMA / W and SLOP / W module, at first analyze the finite element stress with SIGMA / W module, then, the results are imported into the SLOP / W module to calculate the slope stability factor, and compared with the results of using rigid limit equilibrium method. The results show: There is a small difference in slope stability factor in these two methods. Finite element limit equilibrium method can be applied to earth - rock dam slope stability analysis and researches have some reference significance for practical engineering slope stability.
\end{abstract}

\section{Introduction}

Embankment dam slope stability analysis is a key issue in embankment dam engineering design, at present, for the dam slope stability analysis commonly-used methods are rigid limit equilibrium method, finite difference method, finite element method etc. Where the rigid limit equilibrium method is commonly used in quantitative calculation of slope engineering and verified through a large number of practical projects. But because of its slice of soil will be the rigid in the calculation, and ignore deformation and some force between slice and slice, leading to a deviation when calculating of slope stability factor.

With the rapid development of computational mechanics and computer hardware, it's possible to calculate the material stress and strain with advanced computer [1]. Therefore, we use the finite element limit equilibrium method and the finite element software to build models. Consider the material constitutive relations to get real stress, then analyze the slope stability, and compare the results with the rigid limit equilibrium method to verify the possibility of finite element limit equilibrium method in embankment dam slope stability analysis.

\section{The Basic Principle of a Finite Element Limit Equilibrium Method}

Principle of a finite element limit equilibrium method is basis of finite element analyses slope obtained stress distribution, based on the FEM to calculate the stress distribution, thus identifying the most dangerous sliding surface and its corresponding safety factor [2].

To illustrate the safety factor, investigation of the slider $A B C$ is shown in Figure 1. If the stress distribution in the soil is $\sigma_{i j}(\mathrm{x}, \mathrm{y})$, corresponding normal stress and shear stress on the sliding surface is: $\sigma$ and $\tau$, Then $\sigma$ and $\tau$ resultant force balanced with objects suffered external forces, reflecting the effects of all external forces results in the sliding surface [3].

When a sliding surface of the soil $i$ in the limit equilibrium, take infinitesimal length of the vector along the direction of the sliding surface at that point, shown in Figure 2:

$$
T_{i}=\tau_{i} \Delta l_{i}
$$




$$
R_{i}=-\tau_{f i} \Delta l_{i} / F_{i}
$$

Figure 2 shows:

$$
T_{i}+R_{i}=0
$$

Equation $3 T_{i}$ is Micro element length of the shear stress corresponding internal forces are sliding force, $R_{i}$ is stabilizing force.

Shown in Figure 1 for the entire arc length of the slider points found, the equation shows that the points along the sliding surface have reached the limit equilibrium when the average soil strength reduction factor, adopt Mohr - Coulomb shear strength equation $\left({ }_{f}=\sigma \tan \varphi+c\right)$ shows:

$$
F_{s}=\int_{l}(\sigma \tan \varphi+c) d l / \int_{l} \tau d l
$$

Equation (4) $F_{s}$ for the safety factor, $d l$ for soil slope length i, c is the soil cohesion (kPa), $\varphi$ is the effective angle of internal friction $(\square)$

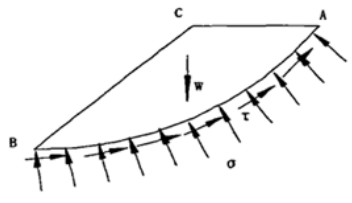

Fig.1 Objects

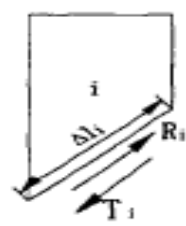

Fig. 2 Soil I

\section{Establish Project Overview and Computational Models}

\section{Project Overview}

Yunnan a total reservoir capacity of 12.2440 million $\mathrm{m}^{3}$, maximum height of dam is $86.1 \mathrm{~m}$. According to "flood control standard" (GB50201-94) and "Water Resources and Hydropower Engineering classification and flood standard" (SL252-2000) ${ }^{[5]}$.The reservoir is a medium-sized projects, and other projects for III, dam raise level of III and other two buildings. The proposed dam is about $10.0 \mathrm{~m}$ in crest width, $58.5 \mathrm{~m}$ in bottom width, and it's reservoir upstream slope is $1: 2.25,1: 2.5,1: 2.75$, Setting two platform, the platform width of $2 \mathrm{~m}$, downstream slope of $1: 2.0,1$ : $2.25,1: 2.5,1: 1.75$, set three platforms, platform width of $2 \mathrm{~m}$, downstream slope for the sub-grid grass slope and the prism of drainage, filter material is $0.5 \mathrm{~m}$ sand and $0.5 \mathrm{~m}$ gravel layer. Clay core top of the wall width $5.00 \mathrm{~m}$, bottom width of $58.0 \mathrm{~m}$, on the downstream slope is $1: 0.3 .3 .0 \mathrm{~m}$ thick located upstream mixing anti-filter, located downstream of sand and gravel two anti-media, thickness are $2.0 \mathrm{~m}$.

\section{Material Parameter Selections}

Table 1 shows the parameters of embankment dam all materials:

Tab.1 Material parameters

\begin{tabular}{|c|c|c|c|}
\hline Dam parts & Severe $/\left(\mathrm{kN} \cdot \mathrm{m}^{\wedge} 3\right)$ & Cohesion $/(\mathrm{kPa})$ & Angle of internal friction/( $\square)$ \\
\hline Upstream of the dam & 22.11 & 47.6 & 30.9 \\
\hline Downstream of the dam & 22.13 & 43.9 & 30.8 \\
\hline Hybrid filter layer & 21.6 & 0 & 28 \\
\hline Clay core wall & 18.8 & 12.3 & 23.6 \\
\hline Concrete Curtain & 24 & 100 & 30 \\
\hline Drainage prism & 19.5 & 0 & 30 \\
\hline Strongly weathered rock & 22 & 30 & 40 \\
\hline Weak weathered rock & 22 & 100 & \\
\hline
\end{tabular}




\section{Build Computational Models}

Employing GEO-STUDIO software, according to the drawings offered by the desing house, considering material partition to establish a calculation model; choosing the model coordinate origin in the lower left corner, $\mathrm{x}$-axis to the right level of positive, $\mathrm{y}$-axis in a vertical upward is positive. The plane quadrilateral element partitioning model to obtain the finite element analysis model, the total number of nodes for 15,966 nodes, the total number of units to 15,771 , the bottom end of the dam fully constrained bedrock, the bedrock on both sides of the border were normal constraints. The final analysis model as shown in Figure 3.

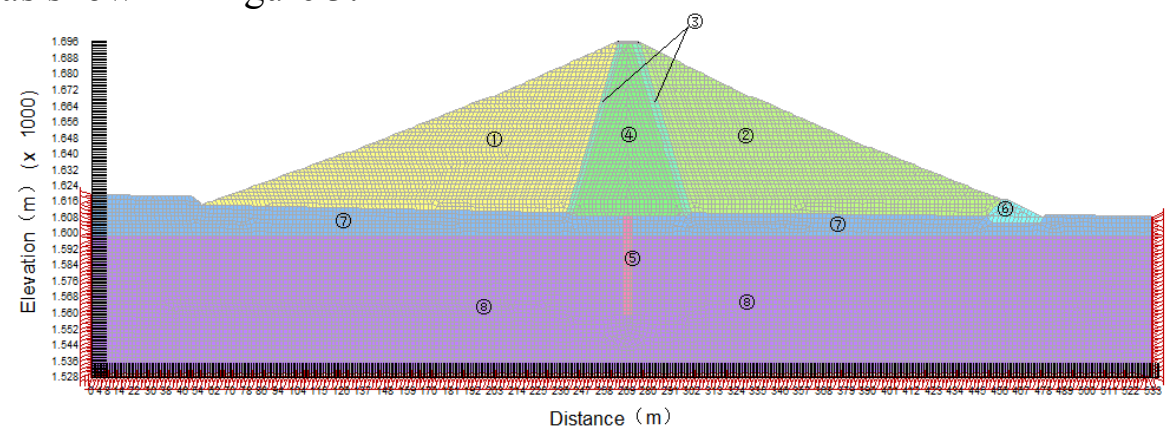

Fig. 3 Calculation Model

\section{Calculate the Results and Analysis}

Calculated results of slope stability based on finite element limit equilibrium method is divided into two parts, one is the use of SIGMA / W module to calculate the results of stress based on The finite element model, another will step on the calculation results of the finite element stress import to SLOP/W module for stability analysis, so as to get the slope stability coefficient.

\section{The Finite Element Stress Analysis}

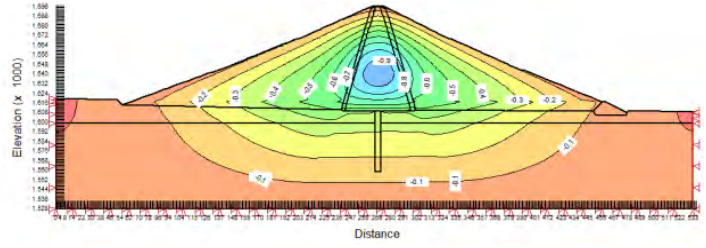

Fig. 4 Vertical Displacement (m)

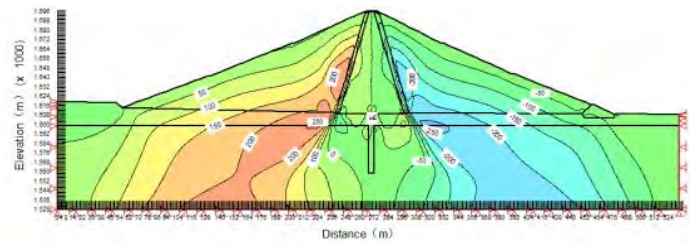

Fig. 5 Model Shear Stress Distribution $(\mathrm{kPa})$

Figure 4 is in full accordance with the process of dam settlement displacement analysis stratified filling construction process, calculations show that after the completion of the dam embankment, maximum vertical subsidence of about $0.9 \mathrm{~m}$, maximum settlement occurs in heart wall in central location value of about one percent dam, in line with the actual engineering in general, which can prove the correctness of finite element results. As can be seen from Figure 5, conditions for the construction of the dam filling finished, the maximum shear stress is $250 \mathrm{kPa}$ inside. Besides shear stress distribute symmetrical distribution of along the sides of the heart wall, because the entire dam distribution and material distribution is substantially symmetrical, in the case of the stress of transition between the shell and the core wall dam, the hybrid filter layer played a good stress transfer effect, the situation does not appear upheaval shear stress, played a very good role in protecting the heart wall.

\section{Slope Stability Calculations}

The dam slope stability is based on the SIGMA / W module finite element stress analysis, then the stress field to be imported into SLOP / W module to calculate limit equilibrium analysis, after the construction of the dam filling finished, analyses slope stability of upstream and downstream. As shown in Figure 6 (a), (c) the results shown gives the upstream slope stability with the finite element 
limit equilibrium method, Figure 6 (b), (d) gives a rigid limit equilibrium method (Bishop) on the downstream side slope stability calculation results. The results of comparison the two methods stable computing in Table 2.

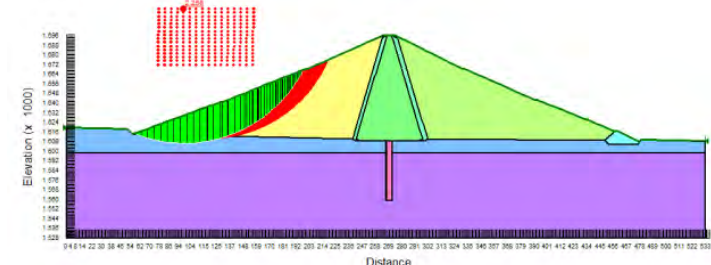

(a) FEM upstream slope stability

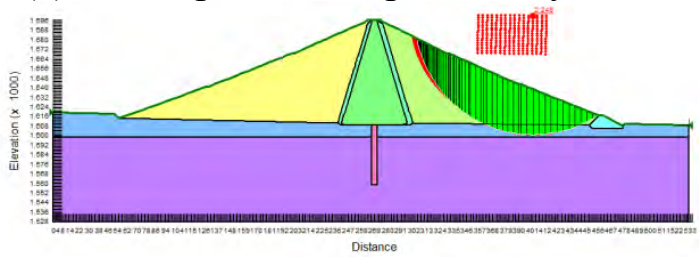

(c) FEM downstream slope stability

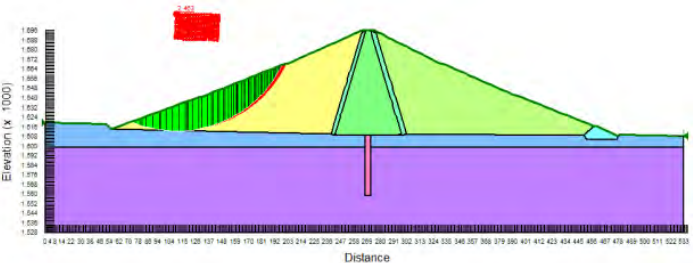

(b) Bishop Method upstream slope stability

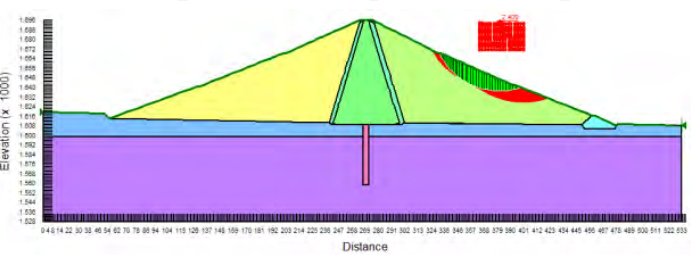

(d) Bishop Method downstream slope stability

Fig.6 Comparison of the Results of the Two Methods

Tab. 2 Comparison of Calculated Results

\begin{tabular}{|c|c|c|}
\hline Slope & FEM limit equilibrium method & Rigid limit equilibrium method (Bishop) \\
\hline Upstream slope & 2.258 & 2.463 \\
\hline Downstream slope & 2.248 & 2.409 \\
\hline
\end{tabular}

Figure 6 shows the results from the comparison, for the downstream slope is calculated using the finite element limit equilibrium method and limit equilibrium method (Bishop Method) are arc-shaped sliding surface, however, sliding surfaces used the finite element limit equilibrium method larger than limit equilibrium method (Bishop). As can be seen from Table 2, the calculated results either way, the upstream slope stability factor is higher than the downstream slope of, because material of the cohesive in the upstream slope is greater than the downstream slope. The same can be seen in the results of the finite element method smaller than limit equilibrium method (Bishop), due to the finite element method considering the stress - strain relations between the strips, but limit equilibrium method (Bishop) ignore the strips of soil between the shearing force and do not meet all of the force in the horizontal direction of the equilibrium conditions of soil, and the soil structure is regarded as rigid, the results have led to some mistakes. Upstream slope stability coefficients used limit equilibrium method and finite element limit equilibrium method (Bishop) were 2.258 and 2.436, downstream slope stability coefficients used the finite element method and limit equilibrium limit equilibrium method (Bishop) were 2.248 and 2.409, both methods stability factor greater than normal conditions in the Specification stability ${ }^{[4]}$ factor 1.25 , its means that the construction of the dam has high security, stability factor of two methods has slightly different, the maximum error is about $9 \%$, indicating that the finite element limit equilibrium method can be used to the slope stability analysis in the construction of embankment dam.

\section{Conclusions}

Through establishing a slope model, with the basic theory of finite element, based on the limit equilibrium analysis method, the calculated stress field is imported into the slope stability analysis, thereby performing the embankment dam downstream and upstream slope stability analysis, and compared with rigid limit equilibrium method. We can draw the following conclusions:

1. Based on the results of finite element limit equilibrium method calculated stability factor compared with rigid limit equilibrium method is slightly different, which is due to the finite element limit equilibrium method takes into account the material constitutive relation between stress and strain, and rigid limit equilibrium method ignore material deformation caused by, but the difference was negligible, so this method can be used to stabilize the embankment dam slope. 
2. The result calculated through the finite element limit equilibrium method and limit equilibrium method on the embankment dam slope stability factor are to meet regulatory requirements, indicating that the dam is completed stability after stratification filling dam down on the downstream an upstream.

\section{References:}

[1]Chen zuyu. Principles and methods [M] soil slope stability analysis of Beijing: China Institute of Water Resources and Hydropower, 2000.

[2]SHAO longtan, LI hongjun, Soil structure stability analysis - FEM limit equilibrium method and its application [M]. Beijing; Science Press, 2011.

[3]ZHOU zibin, Zhang qing, Based on slope limit equilibrium method and finite element method analysis of stability [D], Hehai University Master's thesis, 2004.

[4]Compacted embankment dam design specification (SL274-2001), Beijing: Science Press, 2002

[5]Zhao jie, Shao Longtan, slope stability analysis methods studied several application problems [D], Dalian University of Technology PhD thesis, 2006. 